\title{
INTERNATIONALIZATION OF KNOWLEDGE AND THE ENHANCEMENT OF THE QUALITY AND VISIBILITY OF SCIENTIFIC BRAZILIAN JOURNALS
}

In the last fifteen years, Brazilian scientific journals have been encouraged to internationalize, so that the production of knowledge can be disseminated beyond the countries that speak Portuguese, in order to increase their visibility. The slow and gradual onset occurred mainly with the indexation of journals in recognized databases, such as SciELO, CUIDEN, and LILACS, which absorbed the scientific production of Latin American countries, but also in internationally scoped databases, which reach readers in the English language such as Medline, CINAHL, Scopus and Information Science Institute (ISI).

Those indexations, and others, challenge Brazilian nursing, as the internationalization of the scientific journal is a process that requires planning, dedication, and the financial investment efforts of the editorial team. Several steps need to be performed, the first one of which is assumed that the articles must be in at least two languages where one of them is compulsorily to be in English. They should have open access to be read and should be recognized as carriers of knowledge which are mostly cited. Thereafter, a new application has started that is attracting influential and international researchers who are interested in submitting their manuscripts to journals published in Brazil.

The need to promote the internationalization of Brazilian journals was one of the topics discussed at the Conference that commemorated 15 years of the SciELO Network - Scientific Electronic Library Online, on October 2013 in São Paulo-SP, which brought together specialists researchers and scientific communicators of 25 countries. The scientific director of the SciELO Network, Dr. Rogério Meneghini, based on his study of the international visibility of journals of China, South Korea, Brazil, India, Russia and South Africa, revealed that the collection of Brazilian scientific journals was ranked at fifth place in terms of international citations between those emerging countries, leaving them just ahead of South Africa. He highlighted that the number of articles published in Brazilian journals in English is lower than in the other four countries.

Some nursing journals, especially those that are part of the SciELO collection a few years ago, began publishing articles in English, seeking to increase the visibility and citation of articles by researchers from other countries. There was also a growing incorporation of this practice in other journals that are not part of that network.

The publication in English can be viable by changing the editorial policy of journals. However, the biggest challenge is to attract foreign authors who are interested in publishing their manuscripts in Brazilian journals.

The Text \& Context Journal, after completing its 20 years of existence, reaffirmed its commitment to producing collections with innovative and high quality research, starting from the number 1 volume 21 (Jan/march 2012) with the publication of articles in English, and also maintaining and publishing the article in Portuguese. From that number until March 2014, they already published in their regular numbers, 243 original research articles, 20 reflections, 18 reviews and 11 experience reports in Portuguese/English, Spanish/English or just English. The implementation of this process was gradual and was preceded by a complex planning because it demanded the reorganization of the editorializing of magazines process and the respect of the authors who had already sent their manuscripts, when this editorial policy was not enforced.

The results can already be perceived, for example, in the Google Scholar Citation (http://scholar. google.com.br/citations?viewop=topvenues\&hl=en), the Text \& Context Nursing Journal, is among the three nursing journal with the highest citations and seven among the top 100 most cited journals. The H index of the SCImago Journal \& Country Rank website (http: / / www.scimagojr.com/journalsearch.php?q=01040707\&tip=iss), the journal increased its index from H2 ratio in 2012 to 8 in 2014.

This exponential growth in the number of citations conquered by the Text \& Context Nursing journal, in these two years is certainly due to the decision of its editorial staff to assume the risks of the publication 
also in English; although the responsibility for reviewers and editors increased with regards to the amount of work done by our authors in terms of the costs of publication.

Expanding the number of authors and readers also promotes other aspects including a new perspective for Brazil as a producer of the quality of knowledge that is comparable with the countries who has this practice consolidated; the possibility of multicenter research collaborations; and the internationalization of the Post-Graduate Programs in Nursing, through the exchange of researchers and students in the large scale.

At this point, the editorial team still experience the constant challenge of accelerating the pace of dissemination of knowledge, as prestigious journals should take the initiative to publish innovative, high quality research faster. Therefore, in 2014, the Text \& Context Nursing Journal migrated to the electronic submission and evaluation of manuscripts system called ScholarOne Manuscripts. This is expected to increase the quality of the editorial workflow, the reduction of time between submission and publication of the manuscript, and the link of researchers from different areas of knowledge in different world regions.

It is imperative that the editors of nursing assume the risks and challenges of investing in the essence of their journals, in all aspects that compose them, since only then will they be able to compete equally in the international arena. Certainly, this investment expand their visibility and thus the citation and reading by researchers from different countries, so we can say that we are making a difference with the conviction of being on the right path.

Maria Itayra Padilha

Ph.D. in Nursing. Editor-in-Chief of the Text \& Context Nursing Journal. Dean of the School of Nursing at Universidade Federal de Santa Catarina (UFSC). Post-Doctorate from the University of Toronto, Canada. CNPq Researcher

Odaléa Brüggemann

Ph.D. in Obstetrics and Gynecology. Submission editor of the Text \& Context Nursing Journal. Professor of the School of Nursing and sub-coordinator of the PEN/UFSC. CNPq Researcher

Roberta Costa

Ph.D. in Nursing. Submission editor of the Text $\mathcal{E}$ Context Nursing Journal. Professor of the School of Nursing and of the Professional Master's Degree Program in Management of the Nursing Care at UFSC

Denise Maria Guerreiro Vieira da Silva

Ph.D. in Nursing. Journal manuscript editor of the Text \& Context Nursing Journal. Professor of the School of Nursing and of the PEN/UFSC. Post-Doctorate from the University of Toronto, Canada. CNPq Researcher

Mara Ambrosina Vargas

Ph.D. in Nursing. Journal manuscript editor of the Text \& Context Nursing Journal. Professor of the School of Nursing and of the PEN/UFSC

Selma Regina Andrade

Ph.D. in Nursing. Text and design editor of the Text E Context Nursing Journal. Professor of the School of Nursing and of the PEN/UFSC

Marisa Monticelli

Ph.D. in Nursing. Text and design editor of the Text \& Context Nursing Journal. Retired professor of the School of Nursing and of the PEN/UFSC 